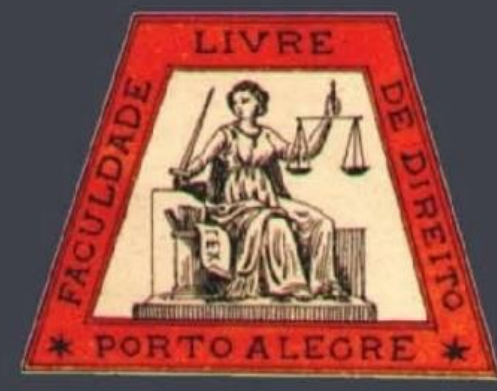

\title{
O ativismo judicial do Supremo Tribunal Federal brasileiro (STF) instrumentalizado pela súmula vinculante, pela ação de descumprimento de preceito fundamental (ADPF) e pelo silêncio
}

The judicial activism of the brazilian federal supreme court instrumentalised by the binding summary, by the action of noncompliance with fundamental precept (ADPF) and by silence

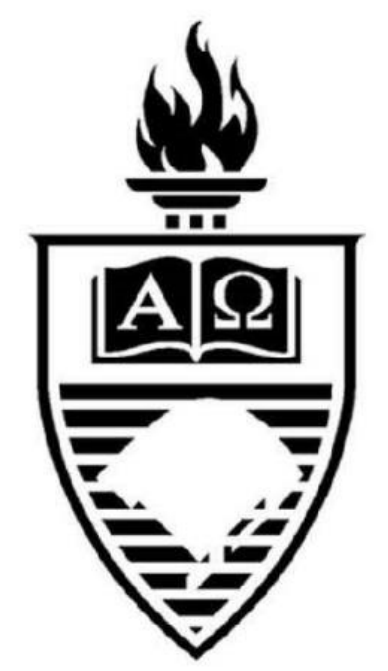

Vidal Serrano Nunes Junior Pontifícia Universidade Católica de São Paulo e Instituição Toledo de Ensino

\section{Fabiana Aparecida Menegazzo} Cordeiro

Centro Estadual de Educação Tecnológica

\section{Mariana Correa Fernandes}

Instituição Toledo de Ensino

\section{UFRGS}




\title{
O ativismo judicial do Supremo Tribunal Federal brasileiro (STF) instrumentalizado pela súmula vinculante, pela ação de descumprimento de preceito fundamental (ADPF) e pelo silêncio
}

\author{
The judicial activism of the brazilian federal supreme court instrumentalised by the binding \\ summary, by the action of noncompliance with fundamental precept (ADPF) and by silence
}

Vidal Serrano Nunes Junior *

Fabiana Aparecida Menegazzo Cordeiro ${ }^{* *}$

\begin{abstract}
Heloisa Cremonezi ${ }^{* * *}$
REFERÊNCIA

NUNES JUNIOR, Vidal Serrano; CORDEIRO, Fabiana Aparecida Menegazzo; CREMONEZI, Heloisa. O ativismo judicial do Supremo Tribunal Federal brasileiro (STF) instrumentalizado pela súmula vinculante, pela ação de descumprimento de preceito fundamental (ADPF) e pelo silêncio. Revista da Faculdade de Direito da UFRGS, Porto Alegre, n. 38, p. 86-100, ago. 2018.
\end{abstract}

\section{RESUMO}

O presente estudo tem por objetivo demonstrar o trabalho do Supremo Tribunal Federal brasileiro (STF) como órgão praticante do Ativismo Judicial, destacando três frentes de atuação, dentre as formas em que se identificam estas práticas: a ação por meio dos instrumentos legais da Ação de Descumprimento de Preceito Fundamental, da Súmula Vinculante e ainda, pela inércia estratégica do STF quando não entrega o resultado da análise jurisdicional dos conflitos que lhe são submetidos, no tempo considerado adequado, face à dinâmica de trabalho da Suprema Corte Brasileira. A abordagem inicia-se com considerações acerca do papel das Cortes Constitucionais de forma abrangente, seguida pelo enfoque ao Supremo Tribunal Federal, sua concepção formal e os trabalhos que vem realizando sob à luz do Neoconstitucionalismo. O trabalho se desenvolve com o detalhamento dos instrumentos utilizados pela Corte Brasileira para julgamento e posicionamento acerca das inúmeras questões que recebem para julgar, sobretudo as mais polêmicas e complexas, destacando-se a ADPF, a Súmula Vinculante e o Silêncio do órgão supremo na execução de seus trabalhos. Demonstra-se as particularidades de cada um destes instrumentos, que se caracterizam como formas essenciais para o exercício do ativismo judicial pelo Supremo Tribunal Federal, ainda que sejam estas, ferramentas consideradas inadequadas ao pleno exercício do Estado

\section{ABSTRACT}

The purpose of this study is to demonstrate the performance of the Brazilian Federal Supreme Court (STF) as a practicing body of Judicial Activism, highlighting three fronts of action, among the various ways in which these practices are identified: action through the legal instruments of the Actions Noncompliance of Fundamental Precept (ADPF), of Binding Precedent and the strategic inertia of the STF when it fails to deliver the result of the jurisdictional analysis of the conflicts submitted to it, at the time considered appropriate, given the dynamics of the Brazilian Supreme Court's work. The approach begins with considerations about the role of Constitutional Courts in a comprehensive way, followed by the approach to the Federal Supreme Court, its formal conception and the work it has been doing under the light of Neo-constitutionalism. The work develops with the detailing of the instruments used by the Brazilian Court for judgment and position on the numerous questions they receive to judge, especially the most controversial and complex ones, standing out the ADPF, Binding Summary and Silence of the supreme body in the execution of their work. The particularities of each of these instruments, which are characterized as essential forms for the exercise of judicial activism by the Federal Supreme Court, although these are tools deemed inadequate to the full exercise of the Democratic State of Right and to the

\footnotetext{
* Professor de Direito Constitucional da Faculdade de Direito da PUC-SP e do Programa de Estudos Pós-Graduados da Instituição Toledo de Ensino de Bauru.

** Professora do Centro Estadual de Educação Tecnológica Paula Souza, Unidade Bauru, e do Curso Técnico em Serviços Jurídicos da Etec Rodrigues de Abreu.

${ }^{* * *}$ Mestranda em sistema constitucional de garantia de direitos na Instituição Toledo de Ensino de Bauru
} 
Democrático de Direito e ao equilíbrio da Tripartição de Poderes, pilastras da atual Constituição Federal.

PALAVRAS-CHAVE

Ativismo Judicial. Preceito Fundamental. Silêncio. Súmula Vinculante. Supremo Tribunal Federal. balance of the Tripartite Powers, pilasters of the current Federal Constitution.

\section{KEYWORDS}

Binding Summary. Judicial Activism. Fundamental Precept. Silence. Brazilian Federal Supreme Court.

\section{SUMÁRIO}

Introdução. 1. Das cortes constitucionais. 2. Do Supremo Tribunal Federal (STF). 3. Do ativismo judicial. 3.1. Da súmula vinculante. 3.2. Da ação de descumprimento de preceito fundamental, a ADPF. 3.3. Do silêncio. Conclusão.

\section{INTRODUÇÃO}

Considerado uma das cortes mais poderosas do mundo, o Supremo Tribunal Federal brasileiro, consolidado pela Constituição Federal do Brasil de 1988, fruto das influências do neoconstitucionalismo, tem exercido com mais evidência o seu ativismo e demonstrado a força do seu poder nos processos de judicialização, não só como a instância maior do Poder Judiciário brasileiro, mas também no exercício da substituição de funções dos Poderes Executivos e Legislativo em descrédito perante a sociedade brasileira, ainda que em situação contramajoritária.

O Neoconstitucionalismo no Brasil é marcado pela presença do Texto Constitucional de 1988 no dia a dia da resolução das demandas sociais fundamentadas nos direitos e garantias constitucionalmente garantidos a todo cidadão brasileiro cansado da opressão do Regime Militar e sedento dos novos ares de liberdade e pleno exercício da Democracia que já bem antes pairava e se efetiva ao longo da Europa. Neste cenário, a presença dos poderes diretamente representantes do povo. A Tripartição de poderes parece ser a forma perfeita de alcance do Estado Democrático de Direito.

No entanto, percalços econômicos e sociais ligados a uma forte crise moral de governabilidade, fez o país perder a direção de aplicação da liberdade alcançada ainda que formalmente pela Constituição Federal de 1988.
Os poderes diretamente representantes do povo apresentam-se submersos à lama da corrupção e o Poder Judiciário, por meio de processos e decisões judiciais se destaca como o meio vislumbrado como possível de resgate da justiça, da segurança jurídica e da credibilidade do país.

Pautas polêmicas que não alcançam quórum de aprovação no Poder Legislativo são transferidas ao Supremo Tribunal federal para serem decididas, por meio da substituição de funções típicas do Poder Judiciário em relação ao Legislativo. Ademais, processos carregados de polêmica chegam ao Judiciário para que, novamente por meio da substituição de função constitucional, seja exercido o papel do Poder Executivo, pois este por ingerência, corrupções e outros desvios de funções, não entregou ao cidadão o serviço que lhe é também constitucionalmente oferecido e garantido, como são exemplos o atendimento judicial às demandas da saúde pública com leitos, remédios e afins.

O presente trabalho, abordará o ativismo judicial no Brasil instrumentalizado pelos mecanismos jurisdicionais utilizados pela Corte Constitucional, sendo os institutos jurídicos da Súmula Vinculante e da Ação De Descumprimento de Preceito Fundamental, a ADPF. Será analisado ainda, o ativismo por meio do silêncio do STF, a inércia proposital do Órgão Supremo mesmo diante da provocação para a resolução de uma demanda judicial.

Pretende-se demonstrar como cada um dos instrumentos constitucionais elencados no 
trabalho são de forma planejada, meios com alto teor de poder e eficácia para o desempenho do ativismo judicial, atuando o STF na substituição dos poderes legislativo e executivo, situação esta que vem sendo fortemente questionada no meio jurídico, mas que independente dos questionamentos, vem sendo utilizada com frequência e propagando inúmeros efeitos que extrapolam a seara do direito, alcançando contornos políticos, econômicos e sociais que marcam o momento histórico pelo qual passa o Brasil.

\section{DAS CORTES CONSTITUCIONAIS}

Conforme descreve FAVOREU ${ }^{1}$, a Corte Constitucional "é uma jurisdição criada para conhecer especial e exclusivamente o contencioso constitucional, situada fora do aparelho constitucional ordinário e independente deste e dos poderes públicos".

Os países ao formarem suas próprias Cortes, sejam influenciadas pelo Modelo Estadunidense, pelo Europeu ou pela mescla de ambos, podem dependendo de sua posição perante o aparelho jurisdicional, tomar postura como Corte Constitucional, apartada deste ou como Corte Suprema, compondo a hierarquia orgânica do Poder Judiciário, no mais alto grau de poder. FAVOREU ${ }^{2}$ complementa sobre a questão do posicionamento da Corte, que independente de sua alocação, se a mesma organicamente tem uma total independência funcional, ela poderá ser considerada Corte Constitucional pelo exercício de suas funções, principalmente na exclusividade de instância da tutela e repressão a direitos fundamentais.

\footnotetext{
${ }^{1}$ FAVOREU, Louis. AS CORTES CONSTITUCIONAIS: trad. Dunia Marinho Silva. São Paulo: Landy Editora, 2004, p.14.

${ }^{2}$ Ibidem, p. 14 e 15.

${ }^{3}$ Ibidem, p. 15.
}

De um modo amplo, o papel das cortes constitucionais em relação as suas influências sobre a ordem jurídica e política do Estado Democrático de Direito, com base em Favoreu ${ }^{3}$ são a Supremacia de poder jurisdicional, que muitas vezes ultrapassa a ordem jurídica, influenciando a ordem política e legislativa, daí o jargão conhecido do "estado de juízes", reconhecendo-se em alguns momentos os poderes ilimitados dos juízes, em relação às autoridades dos demais órgãos, dos demais poderes, uma vez que lhe sobra a instância final de interpretação dos princípios constitucionais aplicáveis às demandas de casos concretos, decorrendo daí a obrigatoriedade de obediência à interpretação, a partir de um posicionamento de unidade interpretacional emanado da Suprema Corte.

Pela posição de Guardiã Supremo da Constituição e por ela ser a baliza mestra de todas as áreas que compõem o Estado Democrático de Direito, no Brasil, o STF atinge alcance e presença em todos os segmentos, inclusive da ordem econômica e financeira destes Estados. Nota-se que com a crise moral dos poderes legislativo e executivo do país, é crescente o empoderamento e a atuação em substituição destes, ou seja, um controle efetivo do Governo e Congresso Nacional brasileiro pelo Poder Judiciário.

O sistema de controle de constitucionalidade é um dos mecanismos de efetivação da guarda da Carta Magna pelas Cortes. A origem deste sistema, a designação de compor as funções típicas das Cortes Constitucionais e os mecanismos de exercício do ativismo judicial remonta a história jurídica e política relatada na obra Federalistas, por meio da qual Hamilton, apud FERREIRA ${ }^{4}$ :

4 FERREIRA, Antônio Oneildo. A natureza contramajoritária da advocacia sob a perspectiva da teoria democrática. Parte 1. Página da OAB - Conselho Federal Disponível em: http://www.oab.org.br/noticia/54939/anatureza-contramajoritaria-da-advocacia-sob-aperspectiva-da-teoria-democratica. 
[...] já previa e afirmava que as limitações decorrentes dos direitos individuais somente poderão ser preservadas na prática através das cortes de justiça, que têm o dever de declarar nulos todos os atos contrários ao manifesto espírito da Constituição. Sem isso, as restrições contra os privilégios ou concessões particulares serão inúteis.

O nobre papel da Corte Constitucional em um Estado Democrático de Direito, de liberdades individuais múltiplas, perpassa a responsabilidade de guardiã formal da Constituição de seu país, cabendo-lhe dosar as limitações aos direitos individuais de cada cidadão, em benefício da manutenção do espírito da Constituição que pode ser entendido como equilíbrio e harmonia social.

\section{DO SUPREMO TRIBUNAL FEDERAL (STF)}

O modelo de ordenamento jurídico hierarquizado brasileiro, com um órgão jurisdicional superior e guardião da lei fundamental do Estado de Direito, tem influências que combina aspectos do sistema americano e do sistema europeu, mais fortemente dos modelos Constitucionais Austríaco e Alemão, que por sua vez também tiveram inspiração Kelseniana, com a formação de Tribunais e Cortes Constitucionais fortes e dotados de ampla competência.

Para o Ministro Barroso, ${ }^{5}$ adotamos do sistema americano, o controle incidental e concreto em que todo juiz ou tribunal interpreta a Constituição ao julgar os casos que lhe são submetidos, podendo inclusive deixar de aplicar norma que considere inconstitucional. Já do

1?utm_source=3766\&utm_medium=email\&utm_campaig n=OAB_Informa. Acesso em 04.abr.2017.

5 BARROSO, Luís Roberto. O papel das Cortes Constitucionais. Disponível em: http://www.luisrobertobarroso.com.br/wp-content/.../Opapel-das-cortes-constitucionais.pdf.

${ }^{6}$ ALARCÓN, Pietro de Jesús Lora. Ciência política, Estado e direito público: uma introdução ao direito público da sistema europeu, adotamos a possibilidade de ajuizamento de ações diretas perante a Suprema Corte, com o controle abstrato, discutindo a constitucionalidade ou não de uma lei.

No Brasil, a Constituição Federal de 1988 determina que é o Supremo Tribunal Federal o seu órgão jurisdicional e lhe confere um conjunto de mecanismos jurisdicionais para exercer esta nobre função. Alarcon, ${ }^{6}$ esclarece que:

\begin{abstract}
[...] o Supremo Tribunal Federal é o guardião da Constituição - caput do artigo 102. Para viabilizar essa orientação são estabelecidas várias ações ou modos de invocar a tutela da Corte com o intuito de que se declare a inconstitucionalidade ou, pelo contrário, a constitucionalidade de um ato ou omissão do poder público.
\end{abstract}

O Ministro Barroso ${ }^{7}$ ao falar sobre o papel das cortes constitucionais nas democracias contemporâneas, em Nova York, discurso transformado em artigo, conforme referenciado, aborda o Judiciário brasileiro como forte $\mathrm{e}$ atuante, com notório desempenho de Suprema Corte, principalmente pelo momento em que passa o país, com significativa judicialização das grandes questões políticas, sociais e morais.

Há situações claras de postura ativista do STF que podem ser observadas nas análises das decisões que se embasam em diferentes linhas de posicionamento. Barroso ${ }^{8}$, elenca exemplos de precedentes de postura ativista do STF:
a) aplicação direta da constituição a situações não expressamente contempladas em seu texto e independentemente de manifestação do legislador ordinário, como se passou em casos como o da imposição de fidelidade partidária e o

contemporaneidade. São Paulo: Editora Verbatim, 2014, p. 348.

7 BARROSO, op. Cit., p.2.

8 BARROSO, Luís Roberto Barroso. O controle de constitucionalidade no direito brasileiro. 7.ed.rev.e atual. São Paulo: Saraiva, 2016, p. 389. 
da vedação do nepotismo; b) a declaração de inconstitucionalidade de atos normativos emanados do legislador, com base e, critérios menos rígidos que os de patente e ostensiva violação da Constituição, de que são exemplos as decisões referentes à verticalização das coligações partidárias e á clausula de barreira; c) a imposição de condutas ou de abstenções ao Poder Público, tanto em caso de inércia do legislador - como no precedente sobre greve no serviço público ou sobre criação de município como no de políticas públicas insuficientes, de que têm sido exemplo as decisões sobre direito à saúde.

O modo de atuar demonstrado pelos exemplos elencados pelo Ministro Barroso, ilustram a atuação do STF em que as decisões criam direito não positivados, distantes da função típica do STF de aplicar a lei vigente.

\section{DO ATIVISMO JUDICIAL}

O Ativismo judicial tem origem na atuação do Poder Judiciário Estadunidense. Barroso, ${ }^{9}$ discorre que foi uma expressão cunhada nos Estados Unidos e que foi empregada como rótulo para qualificar a atuação da Suprema Corte. Na época, entre 1954 e 1969, ocorreu uma profunda revolução a respeito de práticas políticas nos Estados Unidos no que diz respeito aos direitos fundamentais. Estas transformações foram realizadas de forma silenciosa e sem qualquer ato do Congresso ou Decreto presidencial, mas embasada em uma Jurisprudência progressista. O ideal ativista está vinculado a uma atitude mais ampla e intensa do judiciário, com maior interferência no espaço de trabalhos do Executivo e do Legislativo, que em muitas vezes, nem há substituição, mas sim ocupação de espaços vazios, na busca da concretização dos valores e fins constitucionais.

\footnotetext{
9 BARROSO, op.cit. p. 390.

${ }^{10}$ SOUZA JUNIOR, Arthur Bezerra. O ativismo judicial no supremo tribunal federal na garantia do direito à saúde.
}

O ativismo judicial no Brasil pela Suprema Corte tem se consubstanciado por uma nova hermenêutica, que engloba a interpretação e reinterpretação de leis, o preenchimento de lacunas legislativas e de lacunas de ações do executivo. Estes são os pontos principais que busca alcançar o STF para a efetivação dos direitos constitucionalmente consagrados, mas ineficientemente realizados.

Souza Junior, ${ }^{10}$ em trabalho sobre o ativismo de STF brasileiro reforça que atualmente é nítida a transferência para o Supremo Tribunal Federal da competência para se manifestar sobre temas de extrema relevância para o país:

O descrédito nas lideranças legislativa e
executiva do país que em regra tem o expediente
de tratar de temas que emergem como
necessidades sociais à medida que a sociedade se
relaciona, reforçam a recorrência ao Supremo
Tribunal Federal para a resolução de casos que,
constitucionalmente não seriam de sua alçada,
mas que lhe recai a análise e concretização
considerando sua função maior e final de
guardião da Constituição e dos direitos
fundamentais.

A crítica ao fenômeno jurídico do Ativismo Judicial surge na análise mais profunda das práticas do STF quando exerce o poder no sentido de substituir o exercício de uma função que constitucionalmente caberia a outro poder, pela Tripartição de Poderes vigente no Estado Democrático de Direito brasileiro.

Na prática, ainda que ocorra a usurpação do poder judiciário sobre o legislativo e o executivo pela ótica da legalidade, tais atos ganham contornos de legitimidade, à medida que atendem necessidades sociais já há muito tempo do conhecimento dos poderes competentes, porém, sem atendimento, pelas próprias características de situação de Democracia tardia

Disponível

em: https://bibliotecatede.uninove.br/bitstream/tede/1222/2/Art hur\%20Bezerra\%20De\%20Souza\%20Junior.pdf 
em que se encontra o Brasil. A ausência de atendimento de direitos mínimos ao cidadão que garantam a vida com dignidade, faz com que a cidadania prevista na Carta Magna desde 1988 ainda seja precária de fato, colocando no plano social, a prioridade pela necessidade de atendimento destes, independente da instância ou do órgão que os promovam, distanciando o povo do interesse pelo respeito ao princípio da tripartição de poderes.

\subsection{Da Súmula Vinculante}

A Súmula Vinculante está prevista no ordenamento jurídico do Brasil, no art. 103-A da C.F. Este instituto foi inserido no texto da Constituição Federal por meio da Emenda Constitucional $n^{\circ} 45$. Pelo artigo, o STF poderá de ofício, ou por provocação, mediante decisão de $2 / 3$ de seus membros, após reiteradas decisões sobre a matéria, aprovar súmula que produzirá efeito vinculante em relação aos demais órgãos do Poder Judiciário e à administração pública direta e indireta, nas esferas federal, estadual e municipal.

As Súmulas são mecanismos de estabilização, de pacificação da Corte Suprema para eliminar dúvidas quanto à variação de pontos de vista sobre determinado assunto, para se chegar a uma decisão mais correta, mais assertiva, com a uniformização de uma resposta considerada, a mais correta para o caso.

Luiz Alberto David Araújo e Vidal Serrano Nunes Junior ${ }^{11}$, na obra Curso de Direito Constitucional expõem sobre a posição doutrinária de inconstitucionalidade deste instituto, por considerarem que a Súmula Vinculante viola os princípios do Juiz Natural e

\footnotetext{
11 ARAÚJO, Luiz Alberto David; NUNES JÚNIOR, Vidal Serrano. Curso de direito constitucional. $18^{\mathrm{a}} \mathrm{ed}$. Ver.,atual. Até a EC 76 de 28 de novembro de 2013. São Paulo: Editora Verbatim, 2014, p. 477 et.seq.

12 Anotações referente à aula de 04/02/2017, ministrada pelo Prof. Livre Docente Vidal Serrano Nunes Junior, no
}

do Devido Processo Legal. Por esta ótica, uma vez ocorrido o conflito de interesse, estando este sob tipificação de dispositivo previsto em Súmula Vinculante, o resultado desta lide já é conhecido, restando apenas a aplicação de seus efeitos ao caso em concreto.

Também, complementa Vidal Serrano Nunes Junior ${ }^{12}$ que há que se considerar que pela Súmula Vinculante, o Supremo Tribunal Federal emite um Enunciado que se torna abstrato, partindo de uma situação de um caso em concreto, fazendo uma ponte entre os dois tipos de controle constitucionais.

No entanto, a questão foi superada pelo STF que vem utilizando o instituto, baseando-se no art. 130-A, $\S 1^{\circ}$ da Constituição Federal que afirma o objetivo da Súmula Vinculante em definir a validade, a interpretação e a eficácia de normas determinadas, acerca das quais haja controvérsia atual entre órgãos judiciários ou entre estes e a administração pública que acarrete grave insegurança jurídica e relevante multiplicação de processos sobre questão idêntica.

Nota-se pela definição dos objetivos da Súmula Vinculante previstos em lei, a elasticidade do STF na aplicação do instituto, pois ao órgão caberá a interpretação e posicionamento da eficácia de normas das quais esteja havendo controvérsias entre os órgãos judiciários hierarquicamente inferiores e entre estes e o poder executivo, por meio do organograma que compõe a administração pública.

Neste contexto, observa-se a Súmula Vinculante como instrumento de ativismo do STF, pois mediante a análise própria do órgão, no exercício de seu poder discricionário, fará a interpretação e dará as coordenadas de aplicação do instituto conforme o convencimento próprio

Programa de Mestrado "Sistema Constitucional de Garantia de Direitos" do Centro Universitário de Bauru da Instituição Toledo de Ensino, cujo tema abordado foi Jurisdição Constitucional. 
do posicionamento mais adequado para resolução da controvérsia.

Outro ponto a ser destacado é a respeito da possibilidade de revisão da Súmula Vinculante que poderá ser realizada de ofício ou por provocação dos órgãos legitimados, cabendo a revisão ao próprio $\mathrm{STF}$, o mesmo órgão constituinte originário do instituto. Mais uma vez, verifica-se a elasticidade de atuação do STF no processo de revisão de seus próprios atos.

Por fim, como aborda Streck, Abboud ${ }^{13}$ sobre a análise das Súmulas Vinculantes, estas se apresentam como instrumento do ativismo judicial do STF à medida que tanto em sua elaboração quanto em sua aplicação não há a obrigatoriedade do vínculo aos precedentes que deram as bases para a sua formulação, havendo inclusive decisões do STF sobre o mesmo assunto, com linhas de definição divergentes:

\begin{abstract}
A Súmula vinculante, por sua vez, da mesma forma que $o$ assento português, desvincula-se dos casos que a originaram, ela se impõe como um texto normativo de vinculação geral e abstrata para casos futuros tal qual a lei, possui dimensão atemporal, logo, duração indefinida, passando a ter validade após sua publicação na imprensa oficial. [...]. Os precedentes constituem as principais decisões de determinado ordenamento jurídico, cuja função primordial consiste em servir de modelo para decisões posteriores. $\mathrm{O}$ regime de precedentes representa o direito observando a si próprio.
\end{abstract}

O disposto pelo Autor elucida o principal ponto em que a Súmula se destoa do Precedente e com este não deve ser comparada, pois o precedente sempre representará o direito observando a si próprio, retornando às suas origens históricas, já a Súmula da forma em que foi concebida e está sendo aplicada, desvincula-se de seu precedente, sendo caracterizada pela interpretação final do órgão julgador, sem considerar os fatos históricos que geraram sua criação, tampouco as aplicações nos casos anteriores que a esta se atribuiu a fundamentação para a decisão.

\subsection{Da Ação de Descumprimento de Preceito Fundamental (ADPF)}

O dinamismo e a complexidade que abarcam as relações sociais de uma sociedade estruturada em um Estado Democrático de Direito, aumentam a quantidade das demandas judiciais para a resolução dos conflitos de interesse. Consequentemente, a provocação do Estado e principalmente do Supremo Tribunal Federal para a resolução destes conflitos também é uma crescente.

A volatilidade das relações sociais e do entendimento que se molda com as influências de tempo, espaço e comportamento humano, dificultam a legislação escrita de estabelecer uma posição pacífica acerca da profundidade e horizontalidade de atingimento dos direitos fundamentais que norteiam a dignidade humana, centro da Carta Magna Brasileira.

Neste contexto, o Constituinte Originário da Constituição Federal Democrática vigente no Brasil, dentre os mecanismos de controle de constitucionalidade, criou o instituto da Ação de Descumprimento de Preceito Fundamental, um instrumento com objetivo principal de fixar as condições, o modo de interpretação e aplicação dos preceitos fundamentais constitucionais, considerando estes, ainda que de conceito amplo e controvertido, os assuntos e temas constitucionais que se violados trazem consequências mais graves para o ordenamento jurídico.

\footnotetext{
${ }^{13}$ STRECK, Lênio Luiz; ABBOUD, Georges. O que é isto - o precedente judicial e as súmulas vinculantes? 3.ed. Porto Alegre: Livraria do Advogado Editora, 2015, p.70.
} 
Barroso ${ }^{14}$ esclarece que as lacunas existentes na Lei 9882/99, bem como na definição do que seja preceito fundamental, transfere ao STF um amplo espaço de conformação do instituto por via de construção jurisprudencial. $\mathrm{O}$ autor complementa que "esse remédio constitucional possa ser projetado para uma dimensão mais elevada, superadora, inclusive de suas motivações inicias".

Neste ínterim, decorre a corrente que idealiza o papel deste instituto como instrumento para o ativismo do Supremo Tribunal Federal, pois a largueza de tratativa da ADPF permite ao STF, com competência exclusiva para seu tratamento, moldá-la às necessidades para o cumprimento das funções jurisdicionais do órgão, ainda que não haja previsão constitucional clara de como resolver o caso ou ponto controvertido. A partir daí o STF ganha espaço para com a aplicação da ADPF, dar os contornos novidadescos necessários a temas não previstos por completo pelo Constituinte Originário, quando da construção da atual Carta Magna.

A ADPF é a modalidade de controle de constitucionalidade que se localiza na forma de controle concentrado e abstrato, ou seja, de competência exclusiva do Supremo Tribunal Federal. Foi positivada pela legislação na CF de $1988^{15}$, em seu art. 102, p.u., e com a Emenda Constitucional $\mathrm{n}^{\circ} 3$ de 1993, foi remunerada para o art. 102, $\S 1^{\circ}$. Em 1999, na ordem jurídica infraconstitucional, foi criada a Lei 9882/1999 que veio tratar do rito processual e julgamento da ADPF. O instituto também encontrou previsão em inúmeras constituições estaduais, que incluíram esse mecanismo dentro da chamada jurisdição constitucional estadual.

\footnotetext{
14 BARROSO, Luís Roberto Barroso. O controle de constitucionalidade no direito brasileiro. 7.ed.. São Paulo: Saraiva, 2016.

${ }^{15}$ Constituição Federal do Brasil. Disponível em: http:// http://www.planalto.gov.br/ccivil_03/constituicao/constitui caocompilado.htm. Acesso em 01.mar.2017.

16 TAVARES, André Ramos Tavares. Arguição De

Descumprimeno De Preceito Fundamental: análise da
}

Seu contexto gera controvérsias por ter deixado em aberto a Carta Magna, sobre o ponto de tratamento da necessidade de lei regimental/regulamentar para a Ação de Descumprimento de Preceito Fundamental. Tal situação abriu precedente para diversos outros pontos que a tornassem discutível quanto ao seu poder de aplicação imediata, eficácia e amplitude dos seus efeitos.

Sobre a aplicação da ADPF, André Ramos Tavares ${ }^{16}$ discorre que se existem mecanismos concretos, como o recurso extraordinário e as ações originárias comuns, e esses só podem viabilizar o respeito a preceito fundamental para casos ajuizados individualmente, a ADPF permanece como solução viável e principal em sua distintividade ${ }^{17}$ própria do controle abstrato.

O Ministro Celso de Mello, apud TAVARES ${ }^{18}$ esclarece em seu posicionamento sobre a robustez do alcance da ADPF quando interpreta o art. $4^{\circ}, \S 1^{\circ}$ da lei $9.868 / 99$, no julgamento do ADPF 17AgRg/AP, de 05/06/2002, declarando a importância de sua correta aplicação sob pena de que se considerado apenas o princípio da subsidiariedade que rodeia o instituto, o prejuízo de sua aplicação pode ferir diretamente a Constituição Federal, pois a ADPF tem seu fundamento na viabilização da realização de direitos básicos, valores essenciais e preceitos fundamentais previstos pela Carta Magna:

\section{[...] o princípio da subsidiariedade não pode - e não deve - ser invocado para impedir o exercício da ação constitucional de arguição de descumprimento de preceito fundamental, eis que esse instrumento está vocacionado a viabilizar, numa dimensão estritamente objetiva, a realização jurisdicional de direitos básicos, de}

evolução do instituto sob a Constituição de 1988. Disponível em http:// www.agu.gov.br/page/download/index/id/647730. Acesso em 01.mar.2017.

${ }^{17}$ Destaque nosso.

${ }^{18}$ Ibidem. 
valores essenciais e de preceitos fundamentais contemplados no texto da Constituição da República. [...] se assim não se entendesse, a indevida aplicação do princípio da subsidiariedade poderia afetar a utilização dessa relevantíssima ação de índole constitucional, o que representaria, em última análise, a inaceitável frustação do sistema de proteção, instituído na Carta Política, de valores essenciais, de preceitos fundamentais e de direitos básicos, com grave comprometimento da própria efetividade da Constituição.

Neste mesmo sentido, André Ramos Tavares ${ }^{19}$, reforça em seu trabalho que, ainda que parcialmente adotado pelo STF, tem-se a decisão de que a ADPF é sempre cabível quando houver a necessidade (interesse público na conformação constitucional do Direito) de um instrumento para combater a determinada lesão à Constituição, em seus preceitos fundamentais, que não possa ser combatida (de forma definitiva, amplamente e com o mesmo grau de satisfação) por meio dos demais instrumentos jurisdicionais existentes, por não terem a mesma expressividade (ou impacto) que a ADPF ( caso paradigmático da omissão inconstitucional), presente o interesse público nesse tipo de solução.

Sobre a vagueza da definição do que seja o preceito fundamental, Barroso ${ }^{20}$ fixa sua posição de que a locução preceito fundamental descreve um conjunto de disposições constitucionais, que mesmo indefinida, inclui as decisões sobre a estrutura básica do Estado, o catálogo de direitos fundamentais e os chamados princípios sensíveis, vinculando a ideia da Constituição como um mecanismo vinculado à proteção dos preceitos constitucionais considerados fundamentais.

19 TAVARES, André Ramos Tavares. Arguição De Descumprimeno De Preceito Fundamental: análise da evolução do instituto sob a Constituição de 1988. Disponível em http:// www.agu.gov.br/page/download/index/id/647730. Acesso em 01.mar.2017.

20 BARROSO, Luís Roberto Barroso. O controle de constitucionalidade no direito brasileiro. 7.ed.. São Paulo: Saraiva, 2016.
Neste mesmo sentido, o artigo 10, da Lei 9882/99 ${ }^{21}$ dispõe que "julgada a ação, far-se-á comunicação às autoridades ou órgãos responsáveis pela prática dos atos questionados, fixando-se as condições e o modo de interpretação e aplicação do preceito fundamental".

Mesmo havendo na doutrina posições bastante contrárias, hoje com base em decisões do STF fica sólida a posição de que a ADPF dever ser aplicada sempre que houver descumprimento à preceito fundamental, pois além de sanar a controvérsia emergente, a ADPF vem determinar como se deve interpretar o preceito fundamental 22 lesado a partir de então, e por isso o entendimento da instrumentalização do Ativismo Judicial do STF, pelo uso da ADPF.

Como exemplo de Ações de Descumprimento de Preceito Fundamental que demonstram não só o ativismo jurisdicional do STF, bem como seu posicionamento contramajoritário, são as ADPF de número $\mathrm{n}^{\circ} 54$ que aborda o tema Aborto de Anencéfalo e a ADPF $n^{\circ} 132$, que trata do reconhecimento da União Homoafetiva e do casamento entre pessoas do mesmo sexo.

\subsection{Do silêncio}

Em complemento aos instrumentos formais que possibilitam o exercício do Ativismo da Suprema Corte Brasileira, de maneira, em determinadas situações imperceptíveis, o STF se utiliza de outro poderoso meio para produzir seus efeitos desejados, o silêncio.

Sem efeitos colaterais ao órgão, no exercício do seu descaracterizado poder político,

21 LEI 9882/99. Dispõe sobre o processo e julgamento da Ação de Argüição de Descumprimento de Preceito Fundamental, nos termos do $\S 1^{\circ}$ do art. 102 da Constituição Federal. Disponível em http://www.planalto.gov.br/ccivil_03/leis/19882.htm. Acesso em 01.mar.2017.

${ }^{22}$ Grifo nosso 
o STF por conveniência, opta por não se manifestar a respeito de casos que recebe para análise e julgamento, considerando, não ser o momento adequado para a palavra final do Judiciário do país, seja por percepção de motivos de extrema comoção social, por questões orçamentárias, econômicas ou mesmo, políticas.

A inércia do STF no exercício jurisdicional constitucional ocorre não só na protelação para o início da análise e julgamento de um processo, mas também nos pedidos de vista dos Ministros para proferirem seus votos. Wernek ${ }^{23}$, em palestra proferida no Seminário Direitos Fundamentais e Jurisdição Constitucional da Universidade do Rio de Janeiro UERJ, (informação verbal), declara que mais de $80 \%$ em média dos processos em que são pedidos vistas pelos Ministros, o prazo médio é de um ano e meio para o retorno do caso para julgamento, mas há casos de processo há mais de 12 anos em situação de "com pedido de vistas".

A inércia, ou seja, a não execução da atividade jurisdicional pelo STF quando provocado, não tem previsão legal de sanção que coíba o órgão a se manifestar em tempo que não seja o mais adequado ao seu livre entendimento.

Wernek ${ }^{24}$ complementa que sobre o silêncio da Corte (informação verbal) a abertura legal da possibilidade do STF silenciar sobre determinado caso por um espaço de tempo indefinido the dá um poder de atuação amplo. Diferente de negar um caso considerado desconfortável para julgamento em determinado momento e colocar um ponto final em seu tratamento, silenciar sobre tal e depois de decorrido um período retomá-lo para análise e definição, com ânimos mais assentados, menos

\footnotetext{
${ }^{23}$ WERNECK, Diego. Seminário direitos fundamentais e jurisdição constitucional. Mesa cortes constitucionais e litígios estratégicos. Disponível em https://www.youtube.com/watch?v=YHkebSRn-no.

Publicado em 10.mai.2016. (Informações Verbais extraídas do vídeo em referência).
}

pressão da mídia, cria ambiente menos hostil de trabalho e posicionamento dos Ministros sobre assuntos polêmicos, de transformação social.

De aceitação geral, a justificativa do grande volume de processos para serem analisados pelo STF lhe serve de escudo para a análise dos casos por uma sequência ou ordem, sem critérios claros de organização.

Outro ponto de se ressaltar é que diante da complexidade das relações sociais brasileiras, além da grande quantidade de processos, também em grandes proporções é a variedade de assuntos que chegam ao STF para a análise. Tal situação, somada à discricionariedade e à conveniência na escolha da ordem dos processos para julgar, se torna mais um fator que favorece a manutenção do STF nesta linha de atuação, pois considerado então, o momento adequado para tratar e julgar determinado assunto, é muito provável que haja um processo aguardando sua vez para análise e este então, é destacado da fila de espera para ser objeto de trabalho dos Ministros.

A preocupação é que nem sempre há uma harmonia no tempo do trabalho do STF com a necessidade de obtenção da resposta do conflito de interesse pela parte lesada na lide que aguarda resolução, bem como, do cumprimento do devido processo legal e da entrega satisfatória da resposta judicial justa, que considera o fator tempo, um dos quesitos a serem observados no efetivo exercício jurisdicional de resolução dos conflitos.

Como exemplo do ativismo por meio do silêncio, pode-se apontar em 08 de junho de 2016, quando o Procurador Geral da República Rodrigo Janot $^{25}$, pede ao STF a prisão de integrantes da Cúpula do Partido PMDB, não havendo

24 Ibidem., informação verbal extraída do vídeo em referência.

${ }^{25}$ Correio Braziliense. STF opta pelo silêncio a respeito de pedidos de prisão de caciques do PMDB. Disponível em: http://www.correiobraziliense.com.br/app/noticia/politica/ 2016/06/09/internas_polbraeco,535605. Publicado em 09.jun.2016. 
manifestação por parte dos Ministros, apenas o silêncio.

Outros casos de destaque já citados neste estudo e que também embasam, a inércia estratégica do Órgão Supremo são as ADPF n ${ }^{0} 54$, que foi iniciada em 2004 e teve seu julgamento final somente em 2012 e a ADPF n ${ }^{\circ} 132$ que foi protocolizada em 2008 e teve seu desfecho em 2011.

\section{CONCLUSÃO}

A Corte Constitucional Brasileira exercida pelo Supremo Tribunal Federal, por sua atuação nos últimos anos, tem sido considerada uma das mais fortes cortes do mundo. Em meio às discussões acerca do comportamento e trabalho desempenhado pelo STF, se apresentam contornos de legitimidade e legalidade, ou se estão presentes características de despotismo deste órgão frente aos demais, com desequilíbrio e atingimento do princípio da Tripartição dos Poderes e do efetivo exercício da Democracia, o Órgão Supremo têm prolatado decisões que demonstram atuações claras de Ativismo Judicial instrumentalizados, além de outros, pela Ação de Descumprimento de Preceitos Fundamentais, pela Súmula Vinculante e por vezes, utilizando do silêncio estratégico, com a ausência de manifestação em determinados casos.

Tanto na utilização da ADPF quanto na aplicação da Súmula Vinculante, a presença da competência originária do STF e a função da interpretação e posicionamento da eficácia de normas das quais esteja havendo controvérsias entre os órgãos judiciários hierarquicamente inferiores e entre estes e o poder executivo, revelam forte espaço de discricionariedade e elasticidade na utilização destes institutos como ferramentas do ativismo judicial.

Somado aos instrumentos legais abordados, a inércia do STF frente a casos polêmicos para a determinação discricionária do momento mais adequado para análise e votação de um assunto, postergando decisões, tanto sem iniciar a discussão ou por pedido de vistas com prazos, que duram em média um ano e meio, também demonstram o uso do poder de julgamento da Corte Suprema no exercício do Ativismo Judicial.

No cenário atual de desequilíbrio entre os poderes Executivo e Legislativo, maculados pelo descrédito e pela ingovernabilidade, o apelo moral de um STF forte e presente na resolução de conflitos importantes, tem alcançado apoio e legitimidade da sociedade. A imagem de um órgão constitucionalmente capaz de promover o que é mais justo, na visão da sociedade, se sobrepõe ao próprio respeito formal de independência e harmonia geradas pelo princípio da tripartição de poderes. Em um país de democracia tardia como é o Brasil, em que a efetividade do Estado Democrático de Direito ainda engatinha em diversos aspectos, sobretudo na entrega de direitos mínimos essenciais para a dignidade da pessoa humana, enxergar na instância maior do Judiciário, a possibilidade de salvaguarda de direitos não tutelados e executados pelos poderes Legislativo e Executivo, confortam a sensação de Democracia e Estado de Direito no país.

No entanto, a preocupação latente é para a busca do equilíbrio, já que o exercício das funções típicas da tripartição dos poderes e a existência independente e harmônica entre ambos, são as principais bases que estruturam o Estado Democrático de Direito. A existência de uma pauta legislativa para discussão de assuntos de interesse da Comunidade pelo Poder Legislativo representa a saúde de uma sociedade democrática. Já a substituição constante da atividade legislativa pelo judiciário demonstra debilidade no exercício efetivo da cidadania e consequentemente, pontos de fragilidade da plena Democracia. 


\section{REFERÊNCIAS}

ALARCÓN, Pietro de Jesús Lora. Ciência política, Estado e direito público: uma introdução ao direito público da contemporaneidade. São Paulo: Editora Verbatim, 2014.

ARAÚJO, Luiz Alberto David; NUNES JÚNIOR, Vidal Serrano. Curso de direito constitucional. 18ªed.. São Paulo: Editora Verbatim, 2014.

BRASIL. Constituição Federal de 1988. Constituição da República Federativa do Brasil: promulgada em 5 de outubro de 1988. Disponível em: $\quad<$ http:// http://www.planalto.gov.br/ccivil_03/constituicao/constituicaocompilado.htm>. Acesso em: 01 mar. 2017.

BRASIL. Lei $n^{\circ}$ 9882/99, de 03 de dezembro de 1999. Dispõe sobre o processo e julgamento da Ação de Argüição de Descumprimento de Preceito Fundamental, nos termos do $\S 1^{\circ}$ do art. 102 da Constituição Federal. Disponível em: < http://www.planalto.gov.br/ccivil_03/leis/19882.htm>. Acesso em: 01 mar. 2017

BARROSO, Luís Roberto Barroso. O controle de constitucionalidade no direito brasileiro. 7.ed.. São Paulo: Saraiva, 2016.

O papel das Cortes Constitucionais. Disponível em: http://www.luisrobertobarroso.com.br/wp-content/.../O-papel-das-cortes-constitucionais.pdf. Acesso em: 01 abr. 2017.

Correio Braziliense. STF opta pelo silêncio a respeito de pedidos de prisão de caciques do PMDB. Disponível em: <http://www.correiobraziliense.com.br/app/noticia/politica/2016/06/09/internas_polbraeco,535605. Publicado em 09.jun.2016>. Acesso em: 23 abr. 2017.

FAVOREU, Louis. As Cortes Constitucionais: trad. Dunia Marinho Silva. São Paulo: Landy Editora, 2004.

FERREIRA, Antônio Oneildo. A natureza contramajoritária da advocacia sob a perspectiva da teoria democrática. Parte 1. Página da OAB - Conselho Federal Disponível em: $<$ http://www.oab.org.br/noticia/54939/a-natureza-contramajoritaria-da-advocacia-sob-a-perspectivada-teoria-democratica.

Parte 1?utm_source=3766\&utm_medium=email\&utm_campaign=OAB_Informa>. Acesso em: 04 abr. 2017.

MORAIS, Carlos Blanco de. STF legisla ao criar "mutações constitucionais” diz jurista português. consultor jurídico. Disponível em: <http://www.conjur.com.br/2017-jan-28/stf-legisla-mutacoesconstitucionais-jurista-portugues\#top>. Publicado em 28 jan. 2017. Acesso em: 23 abr. 2017.

NEME, Eliana Franco. O Federalismo como proteção dos direitos fundamentais. Disponível em: <Dialnet-OFederalismoComoSistemaDeProtecaoDosDireitosFundam-4818302.pdf.> Acesso em: 23 abr. 2017. 
SOUZA JUNIOR, Arthur Bezerra de. O ativismo judicial no Supremo Tribunal Federal na garantia do direito à saúde. Disponível em: $<$ https://bibliotecatede.uninove.br/bitstream/tede/1222/2/Arthur\%20Bezerra\%20De\%20Souza\%20Ju nior.pdf>. Acesso em: 10 abr. 2017.

STRECK, Lênio Luiz; ABBOUD, Georges. O que é isto - o precedente judicial e as súmulas vinculantes? 3.ed.. Porto Alegre: Livraria do Advogado Editora, 2015.

TAVARES, André Ramos Tavares. Arguição de Descumprimeno de Preceito Fundamental: análise da evolução do instituto sob a constituição de 1988. Disponível em: <http:// www.agu.gov.br/page/download/index/id/647730>. Acesso em: 01 mar. 2017.

SITTA, Eduardo Brol. O ativismo judicial, legitimidade democrática e a jurisdição constitucional. Disponível em: <https://jus.com.br/artigos/19824/o-ativismo-judicial-legitimidade-democratica-e-ajurisdicao-constitucional/1>. Elaborado em 08/2009. Publicado em 2011. Acesso em: 31 mar. 2017.

WERNECK, Diego. Seminário direitos fundamentais e jurisdição constitucional. Mesa cortes constitucionais e litígios estratégicos. Disponível em: <https://www.youtube.com/watch?v=YHkebSRn-no>. Publicado em: 10 mai. 2016. Acesso em: 22 fev. 2017

Recebido em: 15/05/2017 Aceito em: 28/07/2017 
